\title{
MAKER: How to Make a University Maker Space
}

\author{
Bryan Levy, Georgia Institute of Technology \\ Mr. Ricardo Jose Morocz
}

Ricardo graduated with honors from the University of Florida with a Bachelor's degree in Mechanical Engineering in May of 2014. He started his Master's degree in Mechanical Engineering at the Georgia Institute of Technology in Fall of 2014. He joined the Innovation, Design Reasoning, Engineering Education, and Methods (IDREEM) Lab. Ricardo is currently working on measuring the impact of university maker spaces like the Invention Studio on students' retention in STEM related field, creativity, and engineering design confidence.

\section{Prof. Craig Forest, Georgia Institute of Technology}

Craig Forest is an Associate Professor of Mechanical Engineering at Georgia Tech where he also holds program faculty positions in Bioengineering and Biomedical Engineering. He is a Fellow at the Allen Brain Institute in Seattle WA and he is one of the inaugural recipients of the NIH BRAIN Initiative Grants, a national research effort to invent the next generation of neuroscience and neuroengineering tools. $\mathrm{He}$ is cofounder/organizer of one of the largest undergraduate invention competitions in the US-The InVenture Prize, and founder/organizer of one of the largest student-run prototyping facilities in the US-The Invention Studio. He was named Engineer of the Year in Education for the state of Georgia (2013).

\section{Dr. Robert L. Nagel, James Madison University}

Dr. Robert Nagel is an Assistant Professor in the Department of Engineering at James Madison University. Dr. Nagel joined the James Madison University after completing his Ph.D. in mechanical engineering at Oregon State University. He has a B.S. from Trine University and a M.S. from the Missouri University of Science and Technology, both in mechanical engineering. Since joining James Madison University, Nagel has helped to develop and teach the six course engineering design sequence which represents the spine of the curriculum for the Department of Engineering. The research and teaching interests of Dr. Nagel tend to revolve around engineering design and engineering design education, and in particular, the design conceptualization phase of the design process. He has performed research with the US Army Chemical Corps, General Motors Research and Development Center, and the US Air Force Academy, and he has received grants from the NSF, the EPA, and General Motors Corporation.

\section{Dr. Wendy C. Newstetter, Georgia Institute of Technology}

Dr Wendy C. Newstetter is the Director of Educational Research and Innovation in the College of Engineering at Georgia Tech.

\section{Dr. Kimberly Grau Talley P.E., Texas State University}

Dr. Kimberly G. Talley is an assistant professor in the Department of Engineering Technology, Senior Research Fellow and Maker Space Co-Director for the LBJ Institute for STEM Education and Research at Texas State University, and a licensed Professional Engineer. She received her Ph.D. and M.S.E. from the University of Texas at Austin in Structural Engineering. Her undergraduate degrees in History and in Construction Engineering and Management are from North Carolina State University. Dr. Talley teaches courses in the Construction Science and Management Program, and her research focus is in student engagement and retention in engineering and engineering technology education. Contact: kgt5@txstate.edu

\section{Dr. Shaunna Fultz Smith,}

Dr. Shaunna Smith is an Assistant Professor of Educational Technology in the Department of Curriculum and Instruction at Texas State University. She holds an Ed.D. in Curriculum \& Instruction with an emphasis on technology integration and art education. Her teaching and research explore how the hands-on use of design-based technologies (e.g. digital fabrication, 3D modeling and printing, computer programming, and DIY robotics) can impact multidisciplinary learning that transcends traditional content contexts 
(e.g. arts-based STEM integration). At her free mobile makerspace for K-12 students and teachers, The MAKE Lab (http://themakelab.wp.txstate.edu), she is currently researching how recurring experiences within these design-based technologies impact self-efficacy and positive attitudes toward failure.

\section{Dr. Julie S. Linsey, Georgia Institute of Technology}

Dr. Julie S. Linsey is an Assistant Professor in the George W. Woodruff School of Mechanical Engineering at the Georgia Institute of Technological. Dr. Linsey received her Ph.D. in Mechanical Engineering at The University of Texas. Her research area is design cognition including systematic methods and tools for innovative design with a particular focus on concept generation and design-by-analogy. Her research seeks to understand designers' cognitive processes with the goal of creating better tools and approaches to enhance engineering design. She has authored over 100 technical publications including twenty-three journal papers, five book chapters, and she holds two patents. 


\title{
MAKER: How to Make a University Maker Space
}

\begin{abstract}
Many universities are interested in founding a makerspace, but there is a lack of organized tips and best practices for creating and maintaining a maker space in the university environment. We report on an initial list of best practices to help current and developing university maker spaces thrive and give schools considering establishing their own space an avenue to seek guidance and advice.
\end{abstract}

\section{Introduction}

The growth of the maker movement has caught the attention of the academic community, and globally, academic maker spaces have begun to appear on university campus' to support (both directly and indirectly) the academic mission. Not to say that these spaces did not exist prior to the maker space boon (e.g., Stanford's Product Realization Lab ${ }^{1}$ ) that took place over the last decade, merely that they have started to become more common.

Maker spaces provide a new twist on the classic machine shop that has been commonplace in engineering departments worldwide. Maker spaces tend to lower the barrier to entry by providing spaces for design thinking, hacking, tinkering, and other creative pursuits without office-grade equipment plus, where the plus may include all of the machine shop, welding shop, and fabrication shop equipment as well.

Many institutions have installed or are in the process of installing a space of their own but there is a lack of organized guidance as to where to start, what features have the best impact for students, and what makes the most sense for the institution. Preliminary work has been done looking at several existing spaces and determining unique features to identify different approaches to maker spaces. ${ }^{2-5}$ There has also been work looking at common features found at a larger number of universities looking to find commonalities that could be useful in starting a new space. ${ }^{4}$

The purpose of this paper is to provide insight based on currently available knowledge into the process of starting and maintaining a maker space gathered from firsthand experience at the authors' own institutions, as well as insights gained through related research in university maker spaces done by the authors. The insights given through the paper are not meant to be a comprehensive guide to starting a maker space but rather some initial suggestions when starting a new space. Much more research needs to be completed to provide an empirical basis for the guidelines. 


\section{Where to start?}

Arguably the most difficult part of the entire process is initiating the space and turning it into more than just a coffee talk concept. Starting a new maker space can be intimidating and overwhelming, but with the following tips one should be able to get a new space started in no time:

- Student Involvement is vital in all phases

- Pick an under-utilized, but high-traffic space in a neutral location

- Adaptability is important for a new and growing space

- Culture of the space is important for future growth and sustainability

- Equipment should not be intimidating

\section{Student Involvement is Vital in all Phases}

As a maker space is a fixed physical location, or at least usually fixed, many will tend to concentrate on the space primarily when starting off. They will look into locations around campus that might be available and what machines they should buy. Although these are important aspects of maker spaces, they are not the place to start. Instead you should start by answering the following: What is the space for? Although the language is sometimes different, empirically this boils down to one answer, the students. As such, the space should be designed with the students in mind, and if at all possible, with the help of students.

If the primary use of the space is intended as a supplemental lab space for class work (i.e., curricular use) then the primary driver of the equipment and feel of the space is largely dictated by the anticipated course and course project work. In this case, a survey of faculty stakeholders should be conducted to understand current and desired course and project work. If, however, the space is also intended to be used by students for projects outside of the classroom (i.e., cocurricular or extra-curricular), then the involvement of the students from early in the process can prove to be instrumental in the future success of the maker space. As opposed to an "If you build it, they will come" philosophy, it can prove of use to ask the students for input on the matter in advance as you may find that there is not as big of a desire for a space as anticipated. That's not to say that a maker space would not be a good addition to your university just that the type of space that the students are looking for could be different then you planned, (sewing machines and vinyl cutters instead of CNC mills and lathes).

The involvement of students also plays a crucial role later on the process once the space has become established in maintaining and expanding your maker space. Students can serve various roles in maintaining the space once established such as staff for the space, supervising users and keeping the space clean and safe. They can also help run the space, taking some workload off of the faculty, by making decisions on the direction of the space, allocation of the budget, outreach programs and many other areas. When trying to expand your space, being able to show high 
usage and student interest in the space as well as showing a growing way for students to expand their curricular experience with self-driven learning can be a powerful tool.

\section{Pick an under-utilized, but high-traffic space in a neutral location}

Once you understand the student, faculty, and curricular needs, one should begin looking into the location for the maker space. The "ideal" location will vary depending on needs identified from the stakeholders, and finding the final location will involve comprise between university, college, and departmental constraints. The key in this phase is that one should be creative when looking for space. Remember, the maker space culture is to be adaptive and flexible. In the authors' experiences, under-utilized and low cost spaces tend to work well. For example, Rice's Design Kitchen started from an old cafeteria kitchen, Georgia Tech's Invention Studio started in an old mailroom, James Madison University's xLabs started as a television studio, and Michigan Tech is currently converting an old bowling alley in the basement of the student union into a maker space.

Location can also play a big role in advertising and welcoming new users. If a maker space is to be open to the entire campus, try to identify a neutral location. For example, housing the maker space in an engineering building might make visiting the space more intimidating for nonengineering majors, while using a more global location open to the entire campus population, like in the library or student union, can be more inviting and may actually encourage multidisciplinary use.

Likewise, a more visible and centralized space is good for advertising. By making the space visible to those passing by, students can observe what is happening from a distance, and attracting new student interest may be easier. If possible, utilize large windows or glass walls to allow others to look in for interruption free observing as well as increased safety with higher visibility.

\section{Adaptability is important for a new and growing space}

It is important to remember that due to the nature of these spaces and the culture that accompanies them, your maker space will change with time. Unlike traditional machine shops, these changes can be more significant than moving a piece of equipment to the other side of the room and can include adding equipment to changing locations on campus. It is therefore vital for a successful maker space to be able to make changes and adapt both when changes are wanted and when they are forced upon them.

Changes should not be feared in a maker space however, as oftentimes they are brought about internally from feedback from students and can help make the space more inviting and user friendly. For example, at the author's university the maker space has been established and running for around six years and the space continues to change every semester. These changes 
include rearranging the space to give higher accessibility to more popular machines, changing the operating hours and staffing procedures to keep up with user demand, and even adding rooms to the maker space as it grows.

Your maker space should also be able to adapt to changes that are presented to them externally. For example, the space that you originally select may no longer be available when you want to start building or may be recaptured by the school and you may need to seek a new location. It might arise that during operation you realize that the space is too much for one person to keep up with and it may be necessary to hire on more staff to manage operations and oversee safety. You might also find that following a particular model for your space has not given you the success that you have been hoping for and your space must adapt. Staying flexible and adaptable can therefore be essential as your space grows.

\section{Culture of the space is important for future growth and sustainability}

The background day-to-day operations and the community culture are the keys to keeping a maker space alive and operational. With respect to operation, there are a number of different operational models that can be adopted for a maker space, and the operational model chosen may vary depending on the identified stakeholder needs. Models may be any mix of the following:

- Student managed with faculty/staff oversight,

- Faculty/staff managed, and

- External company managed.

The authors have experience employing the student managed model with faculty/staff oversight and have found that this model allows the students to take ownership of the space with faculty and staff there to advise the growth and development of the space from the school's perspective. The authors believe that fostering student ownership in this way will create a stronger attachment to the space for the students, will create leadership opportunities, will create mentorship and peer-learning opportunities, and will minimize student safety risk through shared oversight responsibilities.

Staffing the space is another question to be addressed in new and growing spaces. One approach is to have the space staffed by students who are trained on the equipment. It is the author's belief that student staffing can create a more open atmosphere that is inviting to new users. Student staff members are granted the leadership and mentorship opportunities mentioned above through peer learning, and consequently, student staff members help to create an inclusive learning community. Additionally, student staffed spaces tend to have more open hours as a result of students' frequently more flexible schedules. At the author's university, these open hours have proven useful in recruiting new users. Finally, depending on your equipment and budget, it can 
be beneficial to hire on a machinist and/or maker space manager to help with repairs and training.

Regardless of the staffing approach taken, the primary function of the staff should concern safety. Through training, mentorship, and appropriate personal protective equipment, a safe, welcoming, and inclusive culture can be developed. For example, at the Invention Studio at Georgia Tech, it was found that by having the safety of the space "the key" to the continued operation of the space, and by having the responsibility of the safety of the users on the student staff, the students were vigilant about maintaining safe operating conditions.

One last aspect not to be overlooked when planning and running a maker space is the funding. The funding required will vary with equipment and space size but there is no set cost of running these spaces. Small spaces can be run on volunteer hours with the cost that of maintaining the equipment. As a space grows, dedicated workers may be needed which plays into the funding model. There are different funding models that may be available and vary depending on your unique circumstance but some suggestions for funding follow:

- Incorporate as a club on campus and apply for funding through the student organization system at one's university,

- Use the maker space academically and pool funding from the academic units with curricular use of the space,

- Apply for funding through NSF programs such as I-CORPS, and

- Seek private or corporate donations or partnerships.

\section{Equipment should not be intimidating}

Finally, a maker space needs equipment. Here, again, one should review the needs of the stakeholders prior to purchasing equipment and supplies. Incorporate student in this process as much as possible as they are more likely to continue using equipment that they request as opposed to equipment presented to them.

Consider the barriers of entry related to the equipment and the location of the equipment. In a new maker space, machines with a steep learning curve such as a CNC mill or lathe may be intimidating to students and may require additional safety oversight than initially planned. This may be counter to the desired culture and openness of the space. Considering smaller plug and play machines such as tabletop 3D printers as well as some smaller end laser cutters and some hand tools may be all that is required to get the space up and running. These machines can be run safely with minimal training and begin to open the door for further manufacturing exploration.

Another key part of your maker space should be free space in the form of workspace. This is crucial space for building and assembling projects and lets the students work collaboratively on 
location. Glass walls allow increased safety and likely reduce barriers to entry thereby encouraging students to engage in the space. Space for students to hang out and work provides opportunities for mentoring. Mobile couches, tables, and white boards allow for flexibility and versatility in the space.

Equipment one may consider includes:

- 3D printers

- Laser cutters and engravers

- Vinyl cutters

- Sewing machines and embroidery machines

- CNC mills, lathes, and routers

- Manual knee mills and lathes

- Band saws, table saws, and routers

- Hand tools such as drills, saws, routers, and grinders

- Projection equipment

- Mobile whiteboards, couches, and work surfaces

\section{Summary}

Now one's space is housed, equipped, and staffed, but there is still work to be done assessment. How does one know that one's space is performing as desired? Some things to consider:

- How many people are being served by the space,

- Is there diversity (age, major, gender, ethnicity) of the user group,

- How many projects and what types of projects are being completed in the space,

- How many return users are there in the space, and

- What do alumni space users have to say about the space, equipment, and culture?

So, there is still work to be done, and at the author's respective spaces, there are efforts currently underway to identify answers to some of these questions through monitoring maker space use, investigating the change in students' design self-efficacy as a result of using maker spaces, and exploring the barriers of entry through ethnographic interviews. Future work will focus on these broader impacts related to student engagement in university maker spaces.

\section{Acknowledgements}

This work has been supported by the National Science Foundation under grant DUE-1431923/ 1431721/ 1432107. Any opinions, findings, and conclusions or recommendations expressed in 
this material are those of the authors and do not necessarily reflect the views of National Science Foundation.

\section{References}

1. Blikstein P. Digital fabrication and 'making' in education: The democratization of invention. FabLabs: Of machines, makers and inventors. 2013:1-21.

2. Wilczynski V. Academic Maker Spaces and Engineering Design. ASEE Annual Conference; 2015; Seattle, WA.

3. Weinmann J. Survey and Analyis of Five Leading University Maker Spaces. Munich, Germany: Mechanical Engineering, Technical University Munich; 2014.

4. Barrett T, Pizzico M, Levy BD, et al. A Review of University Maker Spaces. ASEE Annual Conference; June 14-17, 2015; Seattle, WA.

5. Weinmann J, Farzaneh HH, Lindemann U, Forest CR. Survey and analysis of five leading university maker spaces. ASEE Annual Conference; June 26-29, 2016; New Orleans, LA. 